Pacific Journal of Mathematics

THE ROGERS-RAMANUJAN RECIPROCAL AND MINC'S 


\title{
THE ROGERS-RAMANUJAN RECIPROCAL AND MINC'S PARTITION FUNCTION
}

\author{
GeORge E. ANDREWS
}

The reciprocals of the Rogers-Ramanujan identities are considered, and it it shown that the results yield identities for restricted compositions. The same technique is applied to obtain a generating function for partitions previously treated by $H$. Minc.

1. Introduction. The celebrated Rogers-Ramanujan identities were first presented in their analytic form as follows:

$$
\begin{gathered}
1+\frac{q}{1-q}+\frac{q^{4}}{(1-q)\left(1-q^{2}\right)}+\frac{q^{9}}{(1-q)\left(1-q^{2}\right)\left(1-q^{3}\right)}+\cdots \\
=\prod_{n=0}^{\infty} \frac{1}{\left(1-q^{5 n+1}\right)\left(1-q^{5 n+4}\right)} ; \\
1+\frac{q^{9}}{1-q}+\frac{q^{6}}{(1-q)\left(1-q^{2}\right)}+\frac{q^{12}}{(1-q)\left(1-q^{2}\right)\left(1-q^{3}\right)}+\cdots \\
=\prod_{n=0}^{\infty} \frac{1}{\left(1-q^{5 n+2}\right)\left(1-q^{5 n+3}\right)} .
\end{gathered}
$$

The fascinating story of their discovery by L.J. Rogers [8] and their subsequent rediscovery by S. Ramanujan (see [5; p. 91]) and I.J. Schur [9] has been told many times [1; Ch. 7], [2; Ch. 3], [5; Ch. 6]. P.A. MacMahon [6] and I.J. Schur [9] observed that (1.1) and (1.2) are equivalent to the following assertions in additive number theory:

THEOREM $R_{1}$. The number of partitions of $n$ into parts that differ by at least 2 equals the number of partitions of $n$ into parts of the forms $5 m+1$ and $5 m+4$.

THEOREM $\mathrm{R}_{2}$. The number of partitions of $n$ into parts that differ by at least 2 and contain no ones equals the number of partitions of $n$ into parts of the forms $5 m+2$ and $5 m+3$.

Apart from Schur's two ingenious proofs in [9], all other proofs effectively rely on establishing the following two variable result:

$$
\begin{aligned}
F_{1}(z) & \equiv 1+\sum_{n=1}^{\infty} \frac{z^{n} q^{n^{2}}}{(1-q)\left(1-q^{2}\right) \cdots\left(1-q^{n}\right)} \\
& =\left\{\prod_{n=1}^{\infty} \frac{1}{\left(1-z q^{n}\right)}\right\}\left\{1+\sum_{n=1}^{\infty} \frac{(z q)_{n-1}\left(1-z q^{2 n}\right)\left(-z^{2}\right)^{n} q^{n(5 n-1) / 2}}{(q)_{n}}\right\}
\end{aligned}
$$


where $(A)_{n}=(1-A)(1-A q) \cdots\left(1-A q^{n-1}\right),(A)_{0}=1$.

The reciprocal of $F_{1}\left(-z q^{-1}\right)$ was utilized by Carlitz and Riordan [4; p. 386, eq. (10.7)] in their work on $q$-analogs of two element lattice permutation numbers; however they give no indication that in fact $1 / F_{1}(-z)$ is the generating function for certain simply restricted compositions. In another paper Carlitz [3] treats classes of restricted compositions which he calls "up-down" and "down-up" partitions. These he shows are generated by reciprocals of $q$-analogs of the Olivier functions. In fact arguments similar to those given by Carlitz may be utilized to prove the following assertion.

THEOREM 1. Let $C_{d}(m, n)$ denote the number of representations of $n$ in the form

$$
n=c_{1}+c_{2}+\cdots+c_{m}, \text { where } 1 \leqq c_{i+1} \leqq c_{i}+d .
$$

Then for $d \geqq 0$,

$$
\sum_{m, n \geq 0} C_{d}(m, n) z^{m} q^{n}=\frac{1}{F_{d}(-z)}
$$

where

$$
F_{d}(z)=\sum_{n=0}^{\infty} \frac{q^{d\left(\begin{array}{c}
n \\
2
\end{array}\right)+\left(\begin{array}{c}
n+1 \\
2
\end{array}\right)}}{(q)_{n}} .
$$

We note that $C_{0}(m, n)$ is just the number of partitions of $n$ into $m$ parts and (1.4) reduces to a well-known generating function identity [1; p. 16] since

$$
F_{0}(z)=\prod_{n=1}^{\infty}\left(1+z q^{n}\right), \quad[1 ; \text { p. } 19] .
$$

Let us call a representation of $n$ of the form $c_{1}+c_{2}+\cdots+c_{m}$ where $1 \leqq c_{i+1} \leqq c_{i}+1$ a restricted composition, and let $K_{e}(j ; n)$ (resp. $K_{0}(j ; n)$ ) denote the number of restricted compositions with each $c_{i} \geqq j$ and with an even (resp. odd) number of parts. Also let $L_{e}(j ; n)$ (resp. $L_{0}(j ; n)$ ) denote the number of partitions of $n$ into an even (resp. odd) number of parts each $\equiv \pm j(\bmod 5)$. Then equations (1.1) and (1.2) together with Theorem 1 imply:

THEOREM 2. For all $n \geqq 0$,

$$
\begin{aligned}
& K_{e}(1 ; n)-K_{0}(1 ; n)=L_{e}(1 ; n)-L_{0}(1 ; n) ; \\
& K_{e}(2 ; n)-K_{0}(2 ; n)=L_{e}(2 ; n)-L_{0}(2 ; n) .
\end{aligned}
$$

Both Theorems 1 and 2 will be proved in $\S 2$. In $\S 3$ we apply 
these methods to $H$. Minc's partition function $\nu(1, n)$, the number of representations of $n$ in the form $n=1+c_{1}+c_{2}+\cdots c_{m}$ where $1=c_{0}$ and $c_{i+1} \leqq 2 c_{i}$ for $0 \leqq i \leqq m-1$. Minc [7] reduced an enumeration problem in groupoids to the determination of $\nu(1, n)$, and he provided a recurrence whereby $\nu(1, n)$ could be computed. We shall present the generating function for $\nu(1, n)$ :

\section{THEOREM 3.}

$$
\sum_{n=1}^{\infty} \nu(1, n) q^{n}=\frac{q}{\sum_{j=0}^{\infty} \frac{(-)^{i} q^{2^{j+1}-j-2}}{(1-q)\left(1-q^{3}\right)\left(1-q^{7}\right) \cdots\left(1-q^{2 j-1}\right)}} .
$$

2. The Rogers-Ramanujan reciprocal. We begin by proving Theorem 1. From the definition of $C_{d}(m, n)$ we see that

$$
\begin{aligned}
& \sum_{n \geq 0} C_{d}(m, n) q^{n} \equiv \gamma_{m}=\sum_{c_{1}=1}^{\infty} \sum_{c_{2}=1}^{c_{1}+d} \sum_{c_{3}=1}^{c_{2}+d} \cdots \sum_{c_{m}=1}^{c_{m-1}+d} q^{c_{1}+c_{2}+\cdots+c_{m}} \\
& =\sum_{c_{1}=1}^{\infty} \sum_{c_{2}=1}^{c_{1}+d} \cdots \sum_{c_{m-1}=1}^{c_{m-2}+d} q^{c_{1}+c_{2}+\cdots+c_{m-1}} \frac{\left(q-q^{c_{m-1}+d+1}\right)}{(1-q)} \\
& =\frac{q}{1-q} \gamma_{m-1}-\frac{q^{d+1}}{1-q} \sum_{c_{1}=1}^{\infty} \sum_{c_{2}=1}^{c_{1}+d} \cdots \sum_{c_{m-2}=1}^{c_{m-3}+d} q^{c_{1}+c_{2}+\cdots+c_{m-2}} \frac{\left(q^{2}-q^{2 c_{m-2}+2 d+2}\right)}{\left(1-q^{2}\right)} \\
& =\frac{q}{1-q} \gamma_{m-1}-\frac{q^{d+3}}{(1-q)\left(1-q^{2}\right)} \gamma_{m-2}
\end{aligned}
$$

$$
\begin{aligned}
& \text { 1) } \quad+\frac{q^{3 d+3}}{(1-q)\left(1-q^{2}\right)} \sum_{c_{1}=1}^{\infty} \sum_{c_{2}=1}^{c_{1}+d} \cdots \sum_{c_{m-3}=1}^{c_{m-4}+1} q^{c_{1}+c_{2}+\cdots+c_{m-3}} \frac{\left(q^{3}-q^{3 c_{m-3}+3 d+3}\right)}{\left(1-q^{3}\right)} \\
& =\frac{q}{1-q} \gamma_{m-1}-\frac{q^{d+3}}{(1-q)\left(1-q^{2}\right)} \gamma_{m-2}+\frac{q^{3 d+6}}{(1-q)\left(1-q^{2}\right)\left(1-q^{3}\right)} \gamma_{m-3} \\
& -\frac{q^{6 d+6}}{(1-q)\left(1-q^{2}\right)\left(1-q^{3}\right)} \sum_{c_{1}=1}^{\infty} \sum_{c_{2}=1}^{c_{1}+d} \cdots \sum_{c_{m-4}=1}^{c_{m-5}+d} q^{c_{1}+\cdots+c_{m-4}} \frac{\left(q^{4}-q^{4 c_{m-4}+4 d+4}\right)}{\left(1-q^{4}\right)} \\
& = \\
& \quad
\end{aligned}
$$

Thus applying mathematical induction we may rigorously establish that the above iterative process yields

$$
\sum_{j=0}^{m} \gamma_{m-j} \frac{(-1)^{j} q^{d\left(\begin{array}{l}
j \\
2
\end{array}\right)+\left(\begin{array}{c}
j+1 \\
2
\end{array}\right)}}{(q)_{j}}=\left\{\begin{array}{lll}
0 & \text { if } & m>0 \\
1 & \text { if } & m=0
\end{array}\right.
$$

Hence (2.2) is equivalent to

$$
\sum_{m=0}^{\infty} \gamma_{m} z^{m} \sum_{n=0}^{\infty} \frac{(-1)^{n} q^{d\left(\begin{array}{c}
n \\
2
\end{array}\right)+\left(\begin{array}{c}
n+1 \\
2
\end{array}\right)}}{(q)_{n}}=1
$$

Consequently by (2.3), 


$$
\begin{aligned}
\sum_{n, m \geqq 0} C_{d}(m, n) z^{m} q^{n} & =\sum_{m \geq 0} \gamma_{m} z^{m} \\
& =\frac{1}{F_{d}(-z)} .
\end{aligned}
$$

Therefore Theorem 1 is established.

As we remarked in the introduction, Theorem 2 follows immediately from Theorem 1 and the Rogers-Ramanujan identities. Namely

$$
\begin{aligned}
& \sum_{n=0}^{\infty}\left(K_{e}(1 ; n)-K_{0}(1 . n)\right) q^{n} \\
& =\sum_{n, m \geqq 0} C_{1}(m, n)(-1)^{m} q^{n} \quad \text { (by definition) } \\
& =\frac{1}{F_{1}(1)} \quad(\text { by Theorem 1) } \\
& =\prod_{n=0}^{\infty}\left(1-q^{5 n+1}\right)\left(1-q^{5 n+4}\right) \quad(\text { by }(1.1)) \\
& =\sum_{n=0}^{\infty}\left(L_{e}(1 ; n)-L_{0}(1 ; n)\right) q^{n} \text {. }
\end{aligned}
$$

Equation (1.7) follows immediately from (2.5) when we compare coefficients of $q^{n}$ in the extreme terms. Similarly for (1.8) we see that

$$
\begin{aligned}
\sum_{n=0}^{\infty}( & \left.K_{e}(2 ; n)-K_{0}(2 ; n)\right) q^{n} \\
& =\sum_{n, m \geqq 0} C_{1}(m, n)(-q)^{m} q^{n} \\
& =\frac{1}{F_{1}(q)} \\
& =\prod_{n=0}^{\infty}\left(1-q^{5 n+2}\right)\left(1-q^{5 n+3}\right) \\
& =\sum_{n=0}^{\infty}\left(L_{e}(2 ; n)-L_{0}(2 ; n)\right) q^{n} .
\end{aligned}
$$

3. Minc's partition function. If $\mu_{m}$ denotes the generating function for Minc's partitions with $m$ parts then as in $\S 2$ :

$$
\begin{aligned}
\mu_{m}= & \sum_{c_{1}=1}^{2} \sum_{c_{2}=1}^{2 c_{1}} \cdots \sum_{c_{m}=1}^{2 c_{m-1}} q^{1+c_{1}+c_{2}+\cdots+c_{m}} \\
& =\sum_{c_{1}=1}^{2} \sum_{c_{2}=1}^{2 c_{1}} \cdots \sum_{c_{m-1}=1}^{2 c_{m-2}} q^{1+c_{1}+c_{2}+\cdots+c_{m-2}} \frac{\left(q-q^{2 c_{m-1}+1}\right)}{(1-q)} \\
& =\frac{q}{1-q} \mu_{m-1}-\frac{q}{1-q} \sum_{c_{1}=1}^{2} \cdots \sum_{c_{m-2}=1}^{2 c_{m-3}} q^{1+c_{1}+\cdots+c_{m-2}} \frac{\left(q^{3}-q^{6 c_{m-2}+3}\right)}{\left(1-q^{3}\right)} \\
& =\frac{q}{1-q} \mu_{m-1}-\frac{q^{4}}{(1-q)\left(1-q^{3}\right)} \mu_{m-2}
\end{aligned}
$$




$$
\begin{aligned}
& +\frac{q^{4}}{(1-q)\left(1-q^{3}\right)} \sum_{c_{1}=1}^{2} \cdots \sum_{c_{m-3}=1}^{2 c_{m-4}} q^{1+c_{1}+\cdots+c_{m-3}} \frac{\left(q^{7}-q^{14 c_{m-3}+7}\right)}{\left(1-q^{7}\right)} \\
& =\vdots
\end{aligned}
$$

As before applying mathematical induction we may rigorously establish that the above iterative process yields

$$
\sum_{i=0}^{m} \mu_{m-i} \frac{(-1)^{j} q^{1+3+7+\cdots+\left(2_{j}-1\right)}}{(1-q)\left(1-q^{3}\right)\left(1-q^{7}\right) \cdots\left(1-q^{2-1}\right)}=\left\{\begin{array}{lll}
0 & \text { for } & m>0 \\
q & \text { for } & m=0 .
\end{array}\right.
$$

Therefore as in Theorem 1

$$
\sum_{n=1}^{\infty} \nu(1, n) q^{n}=\sum_{m=0}^{\infty} \mu_{m}=\frac{q}{\sum_{j=0}^{\infty} \frac{(-1)^{j} q^{1+3+7+\cdots+\left(2^{j}-1\right)}}{(1-q)\left(1-q^{3}\right)\left(1-q^{7}\right) \cdots\left(1-q^{2^{j}-1}\right)}}
$$

and this is clearly seen to be equivalent to Theorem 3 once we recall that $\sum_{j=0}^{s}\left(2^{j}-1\right)=2^{s+1}-s-2$.

4. Conclusion. The method here could obviously be applied more generally; for example, the role of 2 in Minc's partitions could clearly be played by any positive integer $k$. Of course similar methods are used by Carlitz [3] to treat up-down and down-up partitions. After first discovering Theorem 1, I had hoped that it might be possible to find similar results in general for

$$
\frac{1}{f_{\mathscr{C}}(-z, q)}
$$

where $f_{\mathscr{E}}(z, q)$ is the two variable generating function for the linked partition ideal $\mathscr{C}$ (see [1; Ch. 8] for an explanation of linked partition ideals). Unfortunately the coefficients are not even positive in general.

There is a natural way of providing a common generalization of Theorems 1 and 3. Namely the difference conditions bounding $c_{i+1}$ can be extended to $1 \leqq c_{i+1} \leqq d+a_{0} c_{i}+a_{1} c_{i-1}+\cdots+a_{j} c_{i-j}$. For example the generating function for representations of $n$ of the form

$$
n=1+1+c_{1}+c_{2}+\cdots+c_{m}
$$

subject to $c_{-1}=c_{0}=1$ and $c_{i+1} \leqq c_{i}+c_{i-1}$ is

$$
\sum_{n=0}^{\infty} \frac{q^{2}}{\frac{q^{u_{1}+\cdots+u_{n}-n}(-1)^{n}}{\left(1-q^{u_{1}-1}\right)\left(1-q^{u_{2}-1}\right) \cdots\left(1-q^{u_{n}-1}\right)}}
$$


where $u_{i}$ are shifted Fibonacci numbers $u_{1}=2, u_{2}=3, u_{n}=u_{n-1}+u_{n-2}$ for $n>2$. In general the Fibonacci exponent $u_{i}-1$ in the generating function will be replaced by the sum of the 1st $i$ terms of the recurrent sequence arising from the recurrence $c_{n+1}=d+a_{0} c_{n}+$ $a_{1} c_{n-1}+\cdots+a_{j} c_{n-j}$.

\section{REFERENCES}

1. G. E. Andrews, The Theory of Partitions, Encyclopedia of Mathematics and Its Applications, Vol. 2, Addison-Wesley, Reading, 1976.

2. —- Partitions: Yesterday and Today, New Zealand Math. Soc., Wellington, 1979.

3. L. Carlitz, Up-down and down-up partitions, Studies in Foundations and Combinatorics, G.-C. Rota ed., Academic Press, New York, 1978, 101-129.

4. L. Carlitz and J. Riordan, Two element lattice permutation numbers and their q-generalization, Duke Math. J., 31 (1964), 371-388.

5. G. H. Hardy, Ramanujan, Cambridge University Press, London and New York, 1940 (Reprinted: Chelsea, New York).

6. P. A. MacMahon, Combinatory Analysis, Vol. 2, Cambridge University Press, London and New York, 1916 (Reprinted: Chelsea, New York).

7. H. Minc, $A$ problem in partitions: enumeration of elements of a given degree in the free commutative entropic groupoid, Proc. Edinburgh Math. Soc., 11 (1959), 223-224. 8. L. J. Rogers, Second memoir on the expansion of certain infinite products, Proc. London Math. Soc., 25 (1894), 318-343.

9. I. J. Schur, Ein Beitrag zur additiven Zahlentheorie und zur Theorie der Kettenbrïche, S.-B. Preuss. Akad. Wiss. Phys.-Math. Kl., 302-321 (Reprinted in I. Schur, Gesammelte Abhandlungen, Vol. 2, 117-136. Springer, Berlin, 1973).

Received March 14, 1980. Partially supported by National Science Foundation Grant MCS-75-19162.

The Pennsylvania State University

UNIVERSITY PARK, PA 16802 


\section{PACIFIC JOURNAL OF MATHEMATICS}

\section{EDITORS}

DONALD BABBITT (Managing Editor)

University of California

Los Angeles, CA 90024

HUGo RossI

University of Utah

Salt Lake City, UT 84112

C. C. MOORE and ANDREW OGG

University of California

Berkeley, CA 94720
J. DugundjI

Department of Mathematics

University of Southern California

Los Angeles, CA 90007

R. FinN and J. Milgram

Stanford University

Stanford, CA 94305

\section{ASSOCIATE EDITORS}
R. ARENS
E. F. BECKENBACH
B. H. NeumanN
F. WOLF
K. YOSHIDA

\section{SUPPORTING INSTITUTIONS}

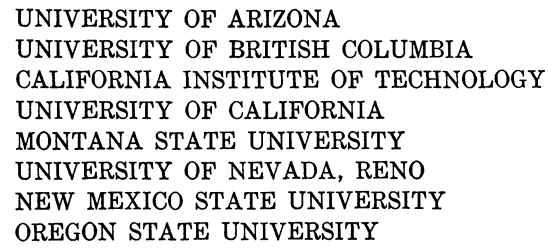

UNIVERSITY OF ARIZONA

UNIVERSITY OF BRITISH COLUMBIA

CALIFORNIA INSTITUTE OF TECHNOLOGY

UNIVERSITY OF CALIFORNIA

MONTANA STATE UNIVERSITY

UNIVERSITY OF NEVADA, RENO

NEW MEXICO STATE UNIVERSITY

OREGON STATE UNIVERSITY

\author{
UNIVERSITY OF OREGON \\ UNIVERSITY OF SOUTHERN CALIFORNIA \\ STANFORD UNIVERSITY \\ UNIVERSITY OF HAWAII \\ UNIVERSITY OF TOKYO \\ UNIVERSITY OF UTAH \\ WASHINGTON STATE UNIVERSITY \\ UNIVERSITY OF WASHINGTON
}

The Supporting Institutions listed above contribute to the cost of publication of this Journal, but they are not owners or publishers and have no responsibility for its content or policies.

Mathematical papers intended for publication in the Pacific Journal of Mathematics should be in typed form or offset-reproduced, (not dittoed), double spaced with large margins. Please do not use built up fractions in the text of the manuscript. However, you may use them in the displayed equations. Underline Greek letters in red, German in green, and script in blue. The first paragraph or two must be capable of being used separately as a synopsis of the entire paper. Please propose a heading for the odd numbered pages of less than 35 characters. Manuscripts, in triplicate, may be sent to any one of the editors. Please classify according to the scheme of Math. Reviews, Index to Vol. 39. Supply name and address of author to whom proofs should be sent. All other communications should be addressed to the managing editor, or Elaine Barth, University of California, Los Angeles, California, 90024.

50 reprints to each author are provided free for each article, only if page charges have been substantially paid. Additional copies may be obtained at cost in multiples of 50 .

The Pacific Journal of Mathematics is issued monthly as of January 1966. Regular subscription rate: $\$ 102.00$ a year (6 Vols., 12 issues). Special rate: $\$ 51.00$ a year to individual members of supporting institutions.

Subscriptions, orders for numbers issued in the last three calendar years, and changes of address shoud be sent to Pacific Journal of Mathematics, P.O. Box 969, Carmel Valley, CA 93924, U.S.A. Old back numbers obtainable from Kraus Per!odicals Co., Route 100, Millwood, NY 10546.

PUBLISHED BY PACIFIC JOURNAL OF MATHEMATICS, A NON-PROFIT CORPORATION

Printed at Kokusai Bunken Insatsusha (International Academic Printing Co., Ltd.). 8-8, 3-chome, Takadanobaba, Shinjuku-ku, Tokyo 160, Japan. 


\section{Pacific Journal of Mathematics}

\section{Vol. 95, No. $2 \quad$ October, 1981}

George E. Andrews, The Rogers-Ramanujan reciprocal and Minc's

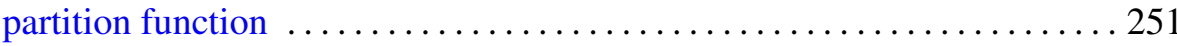

Allan Calder, William H. Julian, Ray Mines, III and Fred Richman,

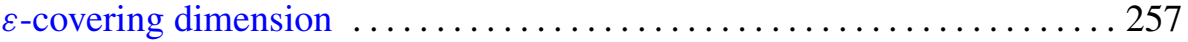

Thomas Curtis Craven and George Leslie Csordas, An inequality for the distribution of zeros of polynomials and entire functions $\ldots \ldots \ldots \ldots 263$

Thomas Jones Enright and R. Parthasarathy, The transfer of invariant

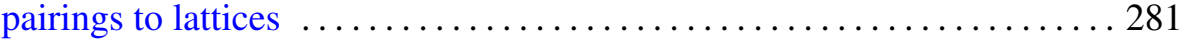

Allen Roy Freedman and John Joseph Sember, Densities and

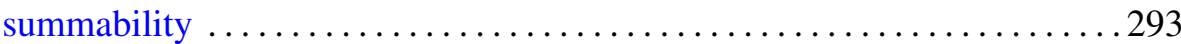

Robert Heller and Francis Aubra Roach, A generalization of a classical necessary condition for convergence of continued fractions . . . . . . 307

Peter Wilcox Jones, Ratios of interpolating Blaschke products ........... 311

V. J. Joseph, Smooth actions of the circle group on exotic spheres ........ 323

Mohd Saeed Khan, Common fixed point theorems for multivalued

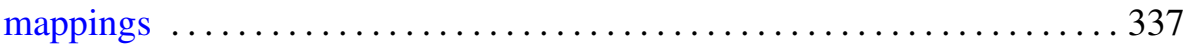

Samuel James Lomonaco, Jr., The homotopy groups of knots. I. How to

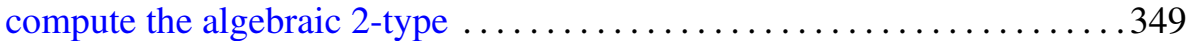

Louis Magnin, Some remarks about $C^{\infty}$ vectors in representations of connected locally compact groups ............................ 391

Mark Mandelker, Located sets on the line . . . . . . . . . . . . . . . . . 401

Murray Angus Marshall and Joseph Lewis Yucas, Linked quaternionic mappings and their associated Witt rings $\ldots \ldots \ldots \ldots \ldots \ldots \ldots \ldots . \ldots \ldots 11$

William Lindall Paschke, $K$-theory for commutants in the Calkin algebra

W. J. Phillips, On the relation $P Q-Q P=-i I$ 435

Ellen Elizabeth Reed, A class of Wallman-type extension. 443

Sungwoo Suh, The space of real parts of algebras of Fourier transforms 461 Antonius Johannes Van Haagen, Finite signed measures on function

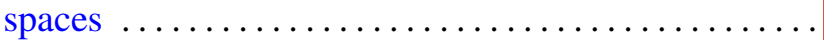

Richard Hawks Warren, Identification spaces and unique uniformity 